\title{
As concepções de formação como ponto de partida e de chegada no MESTRADO PROFISSIONAL EM EDUCAÇÃO da UEMS: revelações e disposições a favor dos processos formativos \\ The conceptions of training as starting point and arrival in the professional master in education of UEMS: revelations and provisions in direction of training processes
}

\author{
Sandra Novais Sousa', Eliane Greice Davanço Nogueira ${ }^{2}$, Cristiane Ribeiro Cabral Rocha ${ }^{3}$
}

\section{Resumo}

O artigo tem como objetivo analisar as concepções de formação evidenciadas nas propostas de intervenção elaboradas na linha de pesquisa Formação de Professores e Diversidade, no período de 2014 a 2018, no Programa de Pós-Graduação Mestrado Profissional em Educação da Universidade Estadual de Mato Grosso do Sul (UEMS). Como procedimentos metodológicos, foram analisados os resumos e as propostas de intervenção de 38 dissertações, à luz dos estudos sobre formação e desenvolvimento profissional docente. Como resultados, aponta-se que, embora haja trabalhos que evidenciam uma concepção de aprendizagem docente em uma perspectiva não transmissiva e verticalizada, persiste a predominância, nas propostas de intervenção, de uma concepção de formação pautada na racionalidade técnica, denominada por Marilyn Cochran-Smith e Susan Lytle de conhecimento-para-a-prática, construída em torno da ideia de cursos, palestras ou oficinas. Conclui-se que as propostas de intervenção, como produção acadêmica que têm alcançado uma importante visibilidade nas secretarias estadual e municipal de educação de Campo Grande/MS, precisam contribuir para uma mudança de compreensão dos processos formativos.
\end{abstract}

Palavras-chave: Mestrado Profissional em Educação. Proposta de intervenção. Concepções de formação.

\begin{abstract}
The article aims to analyze the training conceptions evidenced in the intervention proposals elaborated in the research line Teacher Training and Diversity, from 2014 to 2018, in the Postgraduate Program in Professional Education in the State University of Mato Grosso do Sul (UEMS). As methodological procedures, the abstracts and the intervention proposals of 38 dissertations were analyzed in the light of the studies on teacher training and professional development. As results, it is pointed out that, although there are works that demonstrate a conception of teacher learning in a non-transmissive and verticalized perspective, the intervention proposals predominate, a training conception based on technical rationality, named by Marilyn Cochran- Smith and Susan Lytle of knowledge-for-practice, built around the idea of courses, lectures or workshops. It is concluded that the intervention proposals, such as academic production that have achieved an important visibility in the state and municipal departments of education of Campo Grande / MS, need to contribute to a change of understanding of the formative processes, aiming at the construction of collaborative learning networks and socialization of the knowledge produced by teachers about their professional practice.
\end{abstract}

Keywords: Professional Master's in Education. Proposed intervention. Training conceptions.

\footnotetext{
${ }^{1}$ Mestre e doutora em Educação, Professora da Faculdade de Educação da Universidade Federal de Mato Grosso do Sul (UFMS) http://orcid.org/0000-0002-5965-1954

2 Doutora em Educação, professora do Programa de Pós'-Graduação em Educação da UEMS- http://orcid.org/0000-0002-60679911

${ }^{3}$ Mestre em Educação, professora da rede municipal de ensino de Campo Grande/MS- http://orcid.org/0000-0001-8321-3906

Contato com autor: sandnovais@hotmail.com
} 


\section{INTRODUÇÃO}

O Programa de Pós-Graduação Mestrado Profissional em Educação (Profeduc) da Universidade Estadual de Mato Grosso do Sul iniciou suas atividades no ano de 2013, na unidade universitária de Campo Grande, capital do estado. Possui duas linhas de pesquisa, quais sejam: Organização do Trabalho Didático e Formação de Professores e Diversidade.

Segundo a página oficial do Programa, o Profeduc possui uma proposta que visa contribuir com "[...] a formação de educadores para a educação básica do estado de Mato grosso do sul e demais estados circunvizinhos" (UNIVERSIDADE ESTADUAL DE MATO GROSSO DO SUL, 2019a, p. 1). Assim, uma das exigências para ingresso no Programa é a comprovação de atuação na educação básica como professor, gestor ou coordenador pedagógico, seja na rede pública municipal, estadual ou federal, sendo que no caso da rede estadual foi firmado um convênio (UEMS/ SED-MS no 744/2014) com a Secretaria de Estado de Educação de Mato Grosso do Sul (SED/MS), no qual $40 \%$ das vagas do processo seletivo são disponibilizadas para os educadores vinculados a essa rede.

Um dos diferenciais do Profeduc/UEMS consiste em não denominar de "produto final", assim como ocorre em alguns programas de mestrado profissional, o trabalho produzido como exigência para obtenção do título de mestre ao final do curso. No mestrado profissional em Educação da UEMS os acadêmicos produzem uma dissertação, com o mesmo rigor científico exigido nos programas de mestrado acadêmico, e uma "proposta de intervenção". A opção pelo termo "proposta de intervenção" e não "produto final" remete à ideia de produção não de algo fechado em si mesmo ou acabado, mas de uma proposta para intervir, provocar mudanças ou propor estratégias de ação frente às situações que consistiram em problemas de pesquisa para os mestrandos.

Esse entendimento do Profeduc/UEMS pode contribuir para consolidar uma articulação mais efetiva entre conhecimentos teórico-acadêmicos e prática profissional, em consonância com o conceito de desenvolvimento profissional docente, no qual se entende que a aprendizagem da profissão não se encerra em um processo formativo, seja ele inicial - na graduação/licenciatura - ou contínuo - por meio de especializações, palestras, oficinas, cursos ou demais formas de "treinamento". Na perspectiva do desenvolvimento profissional docente, a aprendizagem se dá ao longo da atuação profissional, quando os docentes utilizam as situações desafiadoras que encontram em seu cotidiano de trabalho para pesquisar, buscar e produzir conhecimentos, a fim de desenvolver, a partir dessa reflexão, novas formas de atuação.

Segundo a Universidade Estadual de Mato Grosso do Sul (2019a, p. 1), dentre as propostas decorrentes das dissertações já defendidas, "[...] cerca de $50 \%$ já foram aplicadas na rede pública de ensino e demonstram seus desdobramentos na organização das redes de ensino, nas secretarias de educação e nas escolas."

Outro diferencial do Profeduc/UEMS é o acompanhamento dos egressos do Programa, por meio da realização dos chamados Seminários Integradores, que são encontros anuais em que participam os mestres formados pelo Programa, acadêmicos que estão cursando o Mestrado Profissional ou cursos de graduação na UEMS e convidados externos, como profissionais da educação básica, técnicos e responsáveis pelos setores de políticas públicas das secretarias municipal e estadual de educação. Nesses encontros, os egressos apresentam "[...] a pesquisa desenvolvida no Programa e sua proposta de intervenção, destacando os desdobramentos/impactos da sua formação como profissional da educação básica." (UNIVERSIDADE ESTADUAL DE MATO GROSSO DO SUL, 2019a, p. 1).

No presente artigo, tomamos como objeto de estudo as propostas de intervenção apresentadas nas dissertações produzidas na linha de pesquisa Formação de Professores e Diversidade do Programa de Pós-Graduação Mestrado Profissional em Educação da UEMS, no período de 2014 a 2018.

Como procedimentos metodológicos, foi realizada a leitura dos resumos e da proposta de intervenção de todas as dissertações, analisadas a partir dos estudos sobre aprendizagem, formação e desenvolvimento profissional docente, sobretudo os de Cochran-Smith e Lytle (1999). 
Encontramos disponíveis no Banco de Teses e Dissertações da UEMS 85 dissertações, dentre as quais 38 trabalhos, o que corresponde a $45 \%$ do total de pesquisas, foram desenvolvidos na linha Formação de Professores e Diversidade e tratam de diversos temas ligados à formação docente, conforme pode ser observado na Tabela 1.

Tabela 1. Temáticas das dissertações do Profeduc, linha "Formação de Professores e Diversidade".

\begin{tabular}{|l|l|l|}
\hline Temática & Autores/ano & Total \\
\hline Educação Especial & $\begin{array}{l}\text { Maciel (2015); Monteiro (2015); Aguena (2015); } \\
\text { Galvão (2016); Costa (2016); Ribeiro (2017); Fer- } \\
\text { reira (2018); Silva (2018) }\end{array}$ & 8 \\
\hline Educação infantil & Vilamaior (2018) & 1 \\
\hline Professores iniciantes & Vilela (2015); Autora 3 (2016) & 2 \\
\hline Direitos humanos & Cristaldo (2015) & 1 \\
\hline $\begin{array}{l}\text { Serviço de Informação } \\
\text { Profissional }\end{array}$ & Marques (2015) & 1 \\
\hline Alfabetização & $\begin{array}{l}\text { Autora1(2014); Kellermann (2016); Mareco } \\
\text { (2018); Streit (2018); }\end{array}$ & 4 \\
\hline Alfabetização cartográfica & Bezerra (2018) & 1 \\
\hline Educação Indígena & $\begin{array}{l}\text { Luiz (2016); Silva Sobrinho (2016); Ventura (2015); } \\
\text { Leal (2018). }\end{array}$ & 4 \\
\hline $\begin{array}{l}\text { Escola pantaneira/Edu- } \\
\text { cação do campo }\end{array}$ & Gonçalves (2018); Silva (2017) & 2 \\
\hline Educação Física & Loureiro (2018) & 1 \\
\hline Políticas públicas & Silva, D. (2016); Lima (2015) & 2 \\
\hline Coordenação pedagógica & Silva, L. (2016); Arruda (2016); Cabral (2017) & 3 \\
\hline Educação Infantil & Ribeiro (2014) & 2 \\
\hline Educação Jovens e Adultos & Vieira (2015); Borges (2018) & 1 \\
\hline Arte/ música & Banzatto (2016); Nogueira (2017) & 2 \\
\hline Educação etnicorracial & Cuore (2016); Henkin (2015) & 2 \\
\hline Gênero e sexualidade & Salgado (2018) & 2 \\
\hline TOTAL & & 2 \\
\hline
\end{tabular}

Fonte: UNIVERSIDADE ESTADUAL DE MATO GROSSO DO SUL (2019b)

A variedade de temáticas pesquisadas pelos mestrandos demonstra que seus espaços de atuação são diversificados: há pedagogos, professores de educação física e arte, licenciados em matemática, professores que atuam na educação de jovens e adultos, educação infantil, primeira e segunda fases do ensino fundamental, ensino médio ou em escolas indígenas localizadas em aldeias de municípios do estado ou no perímetro urbano de Campo Grande. Assim, suas pesquisas fornecem uma ampla visão da educação básica e dos problemas concretos encontrados nas escolas públicas de Mato Grosso do Sul. 
Para apresentação desse estudo, organizamos o artigo em duas seções. Na primeira, discorremos conceitualmente sobre as concepções de formação, sobretudo na perspectiva apresentada pelas pesquisadoras americanas Marilyn Cochran-Smith e Susa Lytle, a fim de contextualizar a análise das propostas de intervenção; na segunda, trazemos os resultados dessa análise e o que sinalizam sobre as concepções de formação e aprendizagem docente.

\section{AS CONCEPÇÕES SOBRE APRENDIZAGEM E FORMAÇÃO DOCENTE SEGUNDO COCHRAN- -SMITH E LYTLE}

A formação dos professores que já atuam profissionalmente tem sido frequentemente associada a ministração de cursos, oficinas, capacitações ou treinamentos, em que um formador exerce "[...] uma ação que supõe necessária para que o aluno adquira uma forma esperada pelas instituições ou pela sociedade, para atuar em um campo profissional." (FIORENTINI; CRECCI, 2013, p. 507).

Esse entendimento de que o conhecimento da prática pedagógica é gerado externa e verticalmente, especialmente por pessoas que, não raro, não participam concretamente do cotidiano das salas de aula da educação básica, como pesquisadores universitários ou técnicos das secretarias de educação, tem sofrido críticas de pesquisadores que investigam o campo da formação docente.

No presente artigo, a fim de analisar as concepções de formação percebíveis nas propostas de intervenção apresentadas no Profeduc, tomaremos como referencial os estudos de Marylin Cochran-Smith e Susan Lytle, pesquisadoras norte-americanas que compreendem que existem, basicamente, três concepções vigentes sobre a aprendizagem docente.

Na concepção que designam como "conhecimento-para-a-prática", a formação dos professores é entendida como transmissão de conhecimento, na perspectiva da racionalidade técnica, em que são ofertados, por meio de oficinas, cursos ou outros tipos similares de capacitações, conteúdos, teorias ou estratégias de ensino que possam provocar modificações ou subsidiar a prática docente. Os problemas educacionais são tratados, assim, como questões técnicas, a serem resolvidas por meio da aplicação de teorias científicas. Sob essa ótica, o professor, nessa concepção, apresenta-se como um receptor passivo, que absorve de um outro, mais experiente e capacitado, o conhecimento necessário para repensar sua prática.

Assim, conforme Carr e Kemmis (1986, p. 70), os professores

[...] não são vistos como profissionalmente responsáveis por fazer decisões e julgamentos em educação, mas somente pela eficiência com a qual eles implementam as decisões feitas por teóricos educacionais; somente com base em seu conhecimento científico sobre a prática educacional, esta poderia ser melhorada.

Uma segunda concepção mencionada pelas autoras norte-americanas, denominada "conhecimento-na-prática", considera que o conhecimento sobre como ensinar seria aprendido de forma tácita por meio da experiência pessoal e imediata, seguindo a premissa do "aprender fazendo", uma vez que a complexidade do contexto em que ocorrem as situações de ensino e aprendizagem não possibilitariam a aplicação homogênea de soluções.

A crítica a essa concepção, na qual os próprios professores são considerados "[...] designers e arquitetos da ação educativa." (FIORENTINI; CRECCI, 2016, p. 507), refere-se ao fato de que ela situa o conhecimento prático produzido pelos professores em contextos locais e isolados, o que pode torná-lo "[...] rotineiro, naturalizado e reprodutivo de relações e práticas, impedindo que o professor e sua docência possam se desenvolver e se transformar continuamente." (FIORENTINI; CRECCI, 2016, p. 511).

O conhecimento poderia assumir um caráter individualista e distanciar-se da teoria, limitando-se às práticas de cada professor, sem relacionar seus efeitos a um contexto social e histórico mais amplo. Seria, portanto, um conhecimento pautado na racionalidade prática, uma vez que o docente tenderia a repetir as ações que considera que venham tendo sucesso no contexto em que as pratica.

A terceira concepção, a que nomeiam de "conhecimento-da-prática", é defendida por Cochran- 
-Smith e Lytle (1999) como um entendimento mais amplo dos processos formativos e de aprendizagem dos docentes. Segundo as autoras, essa perspectiva parte da premissa que as aprendizagens e conhecimentos relevantes que cada professor vivencia em sua prática de ensino podem ser objeto de reflexão e de investigação quando os professores "desprivatizam", ou seja, tiram do âmbito privado, suas práticas, por meio da constituição de uma rede que conecte essa produção em comunidades mais amplas.

De acordo com Cruz e André (2014, p. 188), o conhecimento docente nessa concepção é construído tanto por meio da investigação sistemática sobre o ensino, os alunos, o aprendizado, os conteúdos, o currículo e a escola, como da ação de aprender "[...] colaborativamente, em comunidades de investigação e/ou redes, buscando, com os outros, construir um conhecimento significativo local, em que a investigação é reconhecida como parte de um esforço maior de transformar o ensino, o aprendizado e a escola." (CRUZ; ANDRÉ, 2014, p. 188).

Diante dessa breve contextualização, voltamo-nos para as dissertações produzidas na linha de pesquisa "Formação de professores e diversidade" do Profeduc/UEMS, a fim de compreender qual concepção de formação, dentre as três mencionadas por Cochran-Smith e Lytle, está implícita nas propostas de intervenção.

Na impossibilidade de apresentar todas as propostas, devido aos limites desse artigo, trazemos nos Quadros 1, 2 e 3 uma síntese das propostas de inter- venção das três temáticas que contam com o maior número de trabalhos, a saber: Educação Especial, Alfabetização e Educação Indígena. De cada uma das temáticas, escolhemos uma proposta para proceder a uma análise mais detalhada.

\section{PROPOSTAS DE INTERVENÇÃO DO PRO- FEDUC: QUAL O CONCEITO DE FORMAÇÃO PRIVILEGIADO?}

Dentre as pesquisas que tiveram como tema central a educação especial, Maciel (2015) analisou o trabalho didático desenvolvido na escola de tempo integral para escolarização do aluno com deficiência intelectual, Aguena (2015) e Costa (2016) trataram do ensino a estudantes com deficiência visual, Monteiro (2015) e Ferreiro (2018) investigaram o atendimento de crianças com deficiência na educação infantil, Galvão (2016) tomou como objeto de estudo os cadernos escolares de estudantes com deficiência intelectual do 60 ano do ensino fundamental e Ribeiro (2015) pesquisou a autoformação docente no trabalho com estudantes com altas habilidades/superdotação.

No que se refere às propostas de intervenção produzidas por esses pesquisadores a partir de seus problemas de pesquisa, o Quadro 1 apresenta um panorama geral, trazendo os títulos da dissertação e da proposta, a abrangência ou público alvo e a concepção de formação percebível no que propõem como intervenção. 
Quadro 1. Síntese das propostas de intervenção do Profeduc (2014-2018) - Temática: Educação Especial

\begin{tabular}{|c|c|c|c|c|}
\hline $\begin{array}{l}\text { Autor/ } \\
\text { ano }\end{array}$ & Título da dissertação & $\begin{array}{l}\text { Título da proposta } \\
\text { de intervenção }\end{array}$ & Abrangência & $\begin{array}{l}\text { Concepção de formação } \\
\text { percebível }\end{array}$ \\
\hline $\begin{array}{l}\text { Maciel } \\
(2015)\end{array}$ & $\begin{array}{l}\text { O trabalho didático da } \\
\text { escola de tempo integral } \\
\text { na escolarização do aluno } \\
\text { com deficiência intelec- } \\
\text { tual. }\end{array}$ & $\begin{array}{l}\text { Co-ensino como } \\
\text { estratégia do tra- } \\
\text { balho didático para } \\
\text { a escolarização do } \\
\text { aluno com deficiên- } \\
\text { cia intelectual }\end{array}$ & $\begin{array}{l}\text { Rede municipal } \\
\text { de ensino de } \\
\text { Campo Grande }\end{array}$ & $\begin{array}{l}\text { Conhecimento-da-prática } \\
\text { Proposta: formação de gru- } \\
\text { pos para estudo de caso de } \\
\text { estudantes com deficiência } \\
\text { para elaboração de planos } \\
\text { individuais de ensino. }\end{array}$ \\
\hline Costa (2016) & $\begin{array}{l}\text { O Atendimento Educa- } \\
\text { cional Especializado do } \\
\text { estudante com deficiência } \\
\text { visual: entre o braile e as } \\
\text { tecnologias computacio- } \\
\text { nais. }\end{array}$ & $\begin{array}{l}\text { Formação de Pro- } \\
\text { fessores no Sistema } \\
\text { Braille e suas Grafias } \\
\text { e Tecnologias Com- } \\
\text { putacionais }\end{array}$ & $\begin{array}{l}\text { Rede estadual de } \\
\text { ensino de Campo } \\
\text { Grande }\end{array}$ & $\begin{array}{l}\text { Conhecimento-para-a-prática } \\
\text { Proposta: curso para apren- } \\
\text { dizagem do uso das tecnolo- } \\
\text { gias computacionais }\end{array}$ \\
\hline $\begin{array}{l}\text { Monteiro } \\
\text { (2015) }\end{array}$ & $\begin{array}{l}\text { O processo de inclusão } \\
\text { de crianças com deficiên- } \\
\text { cia na educação infantil: } \\
\text { desafios da prática ped- } \\
\text { agógica. }\end{array}$ & $\begin{array}{l}\text { Estudo da Coleção } \\
\text { Educação Infantil: } \\
\text { Saberes e Prática } \\
\text { da Inclusão para a } \\
\text { melhoria do trabalho } \\
\text { em sala de aula }\end{array}$ & $\begin{array}{l}\text { Técnicos da } \\
\text { Divisão de Edu- } \\
\text { cação Especial e } \\
\text { Divisão de Edu- } \\
\text { cação Infantil da } \\
\text { Semed, que seri- } \\
\text { am responsáveis } \\
\text { em formar os } \\
\text { professores da } \\
\text { rede. }\end{array}$ & $\begin{array}{l}\text { Conhecimento-para-a-práti- } \\
\text { ca. } \\
\text { Proposta: curso para os técni- } \\
\text { cos da Semed que repassari- } \\
\text { am a capacitação aos profes- } \\
\text { sores. }\end{array}$ \\
\hline $\begin{array}{l}\text { Galvão } \\
(2016)\end{array}$ & $\begin{array}{l}\text { A escolarização do es- } \\
\text { tudante com deficiência } \\
\text { intelectual: os cadernos } \\
\text { escolares como recursos } \\
\text { didáticos em análise. }\end{array}$ & $\begin{array}{l}\text { O ensino colaborati- } \\
\text { vo e a formação de } \\
\text { professores: con- } \\
\text { tribuições à inclusão } \\
\text { escolar }\end{array}$ & $\begin{array}{l}\text { Professores do } \\
60 \text { ano do ensino } \\
\text { fundamental, } \\
\text { professores de } \\
\text { apoio e equipe } \\
\text { gestora de uma } \\
\text { escola municipal, }\end{array}$ & $\begin{array}{l}\text { Conhecimento-para- } a \text {-práti- } \\
\text { ca. } \\
\text { Proposta: apresentação de } \\
\text { relatos das experiências que } \\
\text { envolvem as práticas ped- } \\
\text { agógicas do dia a dia dos } \\
\text { professores e estudo dirigido } \\
\text { (teórico) sobre o trabalho } \\
\text { colaborativo. }\end{array}$ \\
\hline $\begin{array}{l}\text { Aguena } \\
(2015)\end{array}$ & $\begin{array}{l}\text { O ensino de artes visuais } \\
\text { para alunos cegos na } \\
\text { escola comum: retratando } \\
\text { trajetórias e experiências. }\end{array}$ & $\begin{array}{l}\text { Produção de ma- } \\
\text { terial didático para } \\
\text { alunos cegos nas } \\
\text { aulas de arte }\end{array}$ & Não informa & $\begin{array}{l}\text { Conhecimento-para-a-práti- } \\
\text { ca. } \\
\text { Proposta: oficina com estudo } \\
\text { teórico e produção de mate- } \\
\text { rial didático }\end{array}$ \\
\hline $\begin{array}{l}\text { Ribeiro } \\
(2017)\end{array}$ & $\begin{array}{l}\text { Uma escalada sinuosa } \\
\text { pelo terreno das narrati- } \\
\text { vas (auto)biográficas em } \\
\text { busca da (re)constituição } \\
\text { docente frente a alunos } \\
\text { com altas habilidades/ } \\
\text { superdotação }\end{array}$ & $\begin{array}{l}\text { Ateliês formativos: } \\
\text { professores de ciên- } \\
\text { cias da natureza e o } \\
\text { Atendimento Educa- } \\
\text { cional Especializado } \\
\text { (AEE) a alunos com } \\
\text { altas habilidades/ } \\
\text { superdotação }\end{array}$ & $\begin{array}{l}\text { Secretaria de } \\
\text { Estado de Edu- } \\
\text { cação (SED/MS) }\end{array}$ & $\begin{array}{l}\text { Conhecimento-da-prática } \\
\text { Proposta: ateliês de for- } \\
\text { mação para estudo coletivo } \\
\text { com os professores para } \\
\text { a proposição de grupos } \\
\text { de estudo e pesquisa para } \\
\text { estudantes com altas habili- } \\
\text { dades/ superdotação }\end{array}$ \\
\hline
\end{tabular}




\begin{tabular}{|c|c|c|c|c|}
\hline $\begin{array}{l}\text { Ferreira } \\
\text { (2018) }\end{array}$ & $\begin{array}{l}\text { Plano Estadual de Edu- } \\
\text { cação de Mato Grosso do } \\
\text { Sul (2014-2024): Atendi- } \\
\text { mento Educacional Es- } \\
\text { pecializado na educação } \\
\text { infantil }\end{array}$ & $\begin{array}{l}\text { Plano Estadual de } \\
\text { Educação de Mato } \\
\text { Grosso do Sul, Lei } \\
\text { no 4.621, de } 22 \text { de } \\
\text { dezembro } \\
\text { de 2014: Meta } 4 \text { - } \\
\text { Educação Especial - } \\
\text { Estratégia 4.2. }\end{array}$ & $\begin{array}{l}\text { Redes estadual } \\
\text { e municipal de } \\
\text { ensino de Campo } \\
\text { Grande/MS }\end{array}$ & $\begin{array}{l}\text { Conhecimento-para- } a \text {-práti- } \\
\text { ca. } \\
\text { Proposta: criar um formulário } \\
\text { como instrumento para le- } \\
\text { vantar o número de crianças } \\
\text { de zero a três anos com defi- } \\
\text { ciência, transtornos globais } \\
\text { do desenvolvimento e altas } \\
\text { habilidades/superdotação. }\end{array}$ \\
\hline Silva (2018) & $\begin{array}{l}\text { O Atendimento Educacio- } \\
\text { nal Especializado para es- } \\
\text { tudantes com deficiência } \\
\text { auditiva/surdez: o uso das } \\
\text { tecnologias assistivas }\end{array}$ & $\begin{array}{l}\text { Grupo de Estudos } \\
\text { sobre Tecnologia } \\
\text { Assistiva (GETA) }\end{array}$ & $\begin{array}{l}\text { Docentes do } \\
\text { Atendimento } \\
\text { Educacional } \\
\text { Especializado da } \\
\text { Rede Municipal } \\
\text { e Estadual de } \\
\text { Ensino que aten- } \\
\text { dem estudantes } \\
\text { com deficiência } \\
\text { auditiva/surdez } \\
\text { e pesquisadores } \\
\text { da educação } \\
\text { especial }\end{array}$ & $\begin{array}{l}\text { Conhecimento-da-prática. } \\
\text { Proposta: criação de um } \\
\text { grupo de estudo sobre tec- } \\
\text { nologia assistiva, disponibi- } \\
\text { lização de um CD-ROM com } \\
\text { os recursos já disponíveis } \\
\text { e elaboração conjunta de } \\
\text { novos recursos. }\end{array}$ \\
\hline
\end{tabular}

Fonte: Universidade Estadual De Mato Grosso Do Sul (2019B)

Podemos observar que dos oito pesquisadores do Profeduc que investigaram questões relativas à educação especial, quatro apresentaram propostas de intervenção que revelaram a concepção de formação e aprendizagem docente que Cochran-Smith e Lytle (1999) denominam de conhecimento-para-a-prática.

Costa (2016), por exemplo, traz a proposta de intervenção "Formação de Professores no Sistema Braille e suas Grafias e Tecnologias Computacionais", que consiste em um curso, com duração de 120 horas, ministrado por profissionais da UEMS e de órgãos parceiros, em que o pré-requisito para participação é o "Domínio básico da escrita e leitura no Sistema Braille e conhecimentos básicos de informática." (COSTA, 2016, 109), sendo inclusive proposto que seja realizada, para inscrição no curso, uma "avaliação de escrita e leitura do Sistema Braille e tecnologias assistivas com a exigibilidade de obtenção de média 6 por parte do inscrito para a realização do curso." (COSTA, 2016, 109).

A concepção de formação priorizada na proposta pauta-se na ideia de repassar um modelo "[...] acerca da forma adequada do emprego das normas técnicas para produção de Braille em seus diversos contextos" (COSTA, 2016, 111) a professores que já dominam o Braille. Não encontramos, na referida proposta, alguma menção à produção colaborativa de conhecimentos para o trabalho com crianças ou estudantes com deficiência visual ou cegueira, ou seja, trata-se de um modelo transmissivo de informações, em que aqueles que detém o conhecimento repassam as informações consideradas necessárias para a modificação da prática dos professores.

Nas dissertações que investigaram a temática da alfabetização, três pesquisadoras trataram de questões relacionadas a avaliações de larga escala, sendo que Kellermann (2016) e Streit (2018) investigaram os contextos de aplicação da Provinha Brasil, avaliação direcionada às crianças do 20 ano do ensino fundamental, e Mareco (2018) estudou a relação entre as formações do Pacto Nacional pela Alfabetização na Idade Certa (Pnaic) e os resultados da Avaliação Nacional da Alfabetização (ANA). Autora 1 (2014) analisou a compatibilidade das matrizes teóricas de dois programas de formação implantados no estado no período de 2012-2016: Pacto Nacional pela Alfabetização na Idade Certa (Pnaic) e Instituto Alfa e Beto, que firmou uma parceria com a Secretaria de Estado de Educação de Mato Grosso do Sul para fornecer materiais didáticos e formação aos professores alfabetizadores da rede estadual de ensino. 
O Quadro 2 apresenta uma síntese desses trabalhos e de suas propostas de intervenção:

Quadro 2. Síntese das propostas de intervenção do Profeduc (2014-2018) - Temática: Alfabetização

\begin{tabular}{|c|c|c|c|c|}
\hline Autor/ano & $\begin{array}{l}\text { Título da dis- } \\
\text { sertação }\end{array}$ & $\begin{array}{l}\text { Título da proposta } \\
\text { de intervenção }\end{array}$ & Abrangência & $\begin{array}{l}\text { Concepção de formação } \\
\text { percebível }\end{array}$ \\
\hline $\begin{array}{l}\text { Kellermann } \\
\text { (2016) }\end{array}$ & $\begin{array}{l}\text { As narrativas } \\
\text { de professoras } \\
\text { alfabetizadoras } \\
\text { desvelando as } \\
\text { implicações da } \\
\text { Provinha Brasil. }\end{array}$ & $\begin{array}{l}\text { Como aproveitar o } \\
\text { caráter diagnóstico } \\
\text { da Provinha Brasil } \\
\text { para promover novas } \\
\text { práticas pedagógicas } \\
\text { de alfabetização? }\end{array}$ & $\begin{array}{l}\text { Professores do } \\
\text { 10 ao 3o ano do } \\
\text { ensino funda- } \\
\text { mental }\end{array}$ & $\begin{array}{l}\text { Conhecimento-da-prática } \\
\text { Proposta: formação de } \\
\text { grupos de estudo para } \\
\text { estudo da matriz teórica da } \\
\text { Provinha Brasil. }\end{array}$ \\
\hline $\begin{array}{l}\text { AUTORA } 1 \\
\text { (2014) }\end{array}$ & AUTORA 1. & AUTORA 1 & $\begin{array}{l}\text { Universidades, } \\
\text { Secretaria } \\
\text { de Estado de } \\
\text { Educação (SED/ } \\
\text { MS) e Secre- } \\
\text { taria Municipal } \\
\text { de Educação } \\
\text { (Semed) }\end{array}$ & $\begin{array}{l}\text { Conhecimento-da-prática. } \\
\text { Proposta: grupos de estudo } \\
\text { na escola, colaborativo nas } \\
\text { escolas, para investigação e } \\
\text { busca de solução conjunta } \\
\text { dos problemas encontrados } \\
\text { na instituição; participação } \\
\text { dos professores nas de- } \\
\text { cisões sobre as políticas } \\
\text { públicas. }\end{array}$ \\
\hline $\begin{array}{l}\text { Mareco } \\
(2018)\end{array}$ & $\begin{array}{l}\text { Avaliação } \\
\text { Nacional da } \\
\text { Alfabetização } \\
\text { sob a ótica das } \\
\text { formações do } \\
\text { Pacto Nacional } \\
\text { pela Alfabet- } \\
\text { ização na Idade } \\
\text { Certa no estado } \\
\text { de Mato Grosso } \\
\text { do Sul entre os } \\
\text { anos de } 2013 \text { a } \\
2016\end{array}$ & Sem título & $\begin{array}{l}\text { Professores do } \\
\text { ciclo de al- } \\
\text { fabetização das } \\
\text { quatro escolas } \\
\text { pesquisada }\end{array}$ & $\begin{array}{l}\text { Conhecimento- pa- } \\
\text { ra-a-prática: Proposta: } \\
\text { organizar oficinas pedagógi- } \\
\text { cas com carga horária de } 40 \\
\text { horas para os professores } \\
\text { do ciclo de alfabetização } \\
\text { das quatro escolas pesqui- } \\
\text { sada. }\end{array}$ \\
\hline Streit (2018) & $\begin{array}{l}\text { Provinha Brasil: } \\
\text { um estudo } \\
\text { sobre a sua } \\
\text { aplicação em } \\
\text { escolas da Rede } \\
\text { Municipal de } \\
\text { Ensino de Cam- } \\
\text { po Grande/MS }\end{array}$ & $\begin{array}{l}\text { Minicurso: avaliação } \\
\text { em larga escala no } \\
\text { contexto escolar }\end{array}$ & $\begin{array}{l}\text { Professores } \\
\text { alfabetizadores, } \\
\text { gestores e equi- } \\
\text { pe pedagógica } \\
\text { das escolas } \\
\text { participantes }\end{array}$ & $\begin{array}{l}\text { Conhecimento-para- } a \text {-práti- } \\
\text { ca: Proposta: minicurso } \\
\text { ministrado pela pesquisa- } \\
\text { dora, organizado em quatro } \\
\text { encontros, com duração } \\
\text { de } 2 \text { horas e atividades a } \\
\text { distância, totalizando } 30 \\
\text { horas de formação }\end{array}$ \\
\hline
\end{tabular}

Fonte: universidade estadual de mato grosso do sul (2019b) 
Para exemplificar uma proposta de intervenção que evidencia em seus pressupostos a concepção de conhecimento-da-prática, destacamos a dissertação de Kellermann (2016), que traz a proposta de intervenção intitulada "Como aproveitar o caráter diagnóstico da Provinha Brasil para promover novas práticas pedagógicas de alfabetização?", destinada aos professores alfabetizadores do 10,2 을 e 3 으 ano do ensino fundamental, com a mediação da equipe pedagógica (coordenação e gestão) e periodicidade mensal ou bimestral, durante o ano letivo. Propõe que haja o "resgate da função diagnóstica da Provinha Brasil"(KELLERMANN, 2016, p. 149), por meio do estudo coletivo, desenvolvido pelos próprios professores, da Matriz de Referência e dos Referenciais Curriculares, em articulação com as teorias de aprendizagem.

Em sua proposta, a autora sugere "[...] que as reuniões sejam feitas a partir dos aspectos que são propriamente avaliados na Provinha Brasil e dos aspectos que não são avaliados ou cobrados por essa atividade, mas que precisam ser trabalhados" e que "[...] seja incluído nas pautas de discussões entre professores e equipe pedagógica das escolas formas de incentivar e promover situações de escrita." (KELLERMANN, 2016, p. 153-154).
Mais do que um estudo de caráter reprodutivista, que visaria à capacitação dos professores e, em última instância, o treinamento das crianças nas habilidades avaliadas na Provinha Brasil, a proposta parte do questionamento do que é avaliado por esse instrumento, do estudo coletivo sobre as aprendizagens que se constituem direitos das crianças e que não são, necessariamente, consideradas nessa avaliação externa.

Observa-se, assim, que a proposta está voltada para o desenvolvimento profissional docente e para a formação de redes de conhecimento, pois não se trata de levar as respostas e transmiti-las aos professores, mas da busca conjunta de soluções para os problemas encontrados no cotidiano da alfabetização.

Por fim, na temática de educação indígena, Silva Sobrinho (2016), Ventura (2015) e Luiz (2016) investigaram questões relacionadas à escolarização dos povos Terena e Leal (2018) analisou como os conteúdos relacionados à cultura e história dos povos indígenas são apresentados no Referencial Curricular para o Ensino Médio e nos livros didáticos utilizados na rede estadual de ensino de Mato Grosso do Sul. 
O Quadro 3 traz uma síntese das propostas de intervenção elaboradas por esses pesquisadores. Quadro 3. Síntese das propostas de intervenção do Profeduc (2014-2018) - Temática: Educação Indígena.

\begin{tabular}{|c|c|c|c|c|}
\hline Autor/ano & $\begin{array}{l}\text { Título da disser- } \\
\text { tação }\end{array}$ & $\begin{array}{l}\text { Título da pro- } \\
\text { posta de inter- } \\
\text { venção }\end{array}$ & Abrangência & $\begin{array}{l}\text { Concepção de formação percebí- } \\
\text { vel }\end{array}$ \\
\hline $\begin{array}{l}\text { Ventura } \\
\text { (2015) }\end{array}$ & $\begin{array}{l}\text { O processo de } \\
\text { alfabetização } \\
\text { na concepção } \\
\text { dos professores } \\
\text { Terena da Aldeia } \\
\text { Bananal }\end{array}$ & $\begin{array}{l}\text { Revendo a } \\
\text { educação indí- } \\
\text { gena }\end{array}$ & $\begin{array}{l}\text { Professores da } \\
\text { Aldeia Bananal }\end{array}$ & $\begin{array}{l}\text { Conhecimento-para-a-prática } \\
\text { Proposta: formação sobre alfabet- } \\
\text { ização bilíngue, língua Terena e } \\
\text { educação indígena }\end{array}$ \\
\hline $\begin{array}{l}\text { Silva Sobrinho } \\
(2016)\end{array}$ & $\begin{array}{l}\text { Jovem indíge- } \\
\text { na Terena de } \\
\text { Mato Grosso do } \\
\text { Sul: identidade, } \\
\text { formação e tra- } \\
\text { jetória }\end{array}$ & $\begin{array}{l}\text { Caminhos para } \\
\text { repensar con- } \\
\text { exões dentre } \\
\text { povos indíge- } \\
\text { nas, formação } \\
\text { de professores, } \\
\text { universidade e } \\
\text { subsídios para } \\
\text { as práticas } \\
\text { pedagógicas }\end{array}$ & $\begin{array}{l}\text { Professores in- } \\
\text { dígenas e não } \\
\text { indígenas }\end{array}$ & $\begin{array}{l}\text { Conhecimento-para-a-prática } \\
\text { Proposta: formação continuada aos } \\
\text { professores. Não informa quem } \\
\text { ministraria. }\end{array}$ \\
\hline Luiz (2016) & $\begin{array}{l}\text { A prática ped- } \\
\text { agógica de pro- } \\
\text { fessores Terena: } \\
\text { o uso de "temas } \\
\text { geradores" no } \\
\text { processo de al- } \\
\text { fabetização }\end{array}$ & $\begin{array}{l}\text { Caminhos para } \\
\text { a Implemen- } \\
\text { tação da Edu- } \\
\text { cação Escolar } \\
\text { Indígena Bilín- } \\
\text { gue - Aldeia } \\
\text { Bananal, MS }\end{array}$ & $\begin{array}{l}\text { Professores al- } \\
\text { fabetizadores } \\
\text { indígenas }\end{array}$ & $\begin{array}{l}\text { Conhecimento-para-a-prática } \\
\text { Proposta: formação continuada ba- } \\
\text { seada no método de alfabetização } \\
\text { de Paulo Freire. }\end{array}$ \\
\hline Leal (2018) & $\begin{array}{l}\text { Educação, currí- } \\
\text { culo e diferenças: } \\
\text { uma análise da } \\
\text { temática indígena } \\
\text { no Referencial } \\
\text { Curricular e nos } \\
\text { livros didáticos } \\
\text { do ensino médio } \\
\text { de Mato Grosso } \\
\text { do Sul }\end{array}$ & Sem título & Não indicado & $\begin{array}{l}\text { Conhecimento-para- } a \text {-prática } \\
\text { Proposta: indicações de materiais } \\
\text { e atividades didáticos-pedagógicas } \\
\text { pré-selecionadas, que apresentam } \\
\text { as culturas e histórias dos povos } \\
\text { indígenas no Brasil em território } \\
\text { sul-mato-grossense }\end{array}$ \\
\hline
\end{tabular}

Fonte: Universidade Estadual de Mato Grosso do Sul (2019b) 
A concepção de aprendizagem e formação docente predominante nas propostas de intervenção desenvolvidas a partir dessa temática foi a que Cochran Smith e Lytle (1999) denominam de conhecimento-para-a-prática.

Leal (2018), por exemplo, apresenta uma proposta que traz, inicialmente, uma síntese dos resultados de sua pesquisa, na qual analisou o Referencial Curricular para o Ensino Médio e o tratamento dado nos livros didáticos utilizados em escolas estaduais à temática da educação indígena. Em seguida, apresenta um quadro com a seleção de "[...] materiais e/ou atividades didático-pedagógicas que apresentam as culturas e histórias dos povos indígenas no Brasil em território sul-mato-grossense", indicando "as obras a serem trabalhadas por professores (as) e estudantes dentro e fora da escola." (LEAL, 2018, p. 110). A concepção técnica do trabalho docente, em que se compreende que é preciso fornecer ao professor as informações necessárias para que possa modificar ou aperfeiçoar sua prática pode ser percebida na referida proposta:

A maior parte dos materiais e/ou atividades didático-pedagógicas indicadas são de fácil acesso de professores (as) e estudantes, por meio da Internet e/ou materiais pertencentes ao acervo das escolas públicas (DVD TV Escola) desconhecidos de parte dos (as) profissionais da educação. Esses materiais e/ou atividades oportunizam a reflexão sobre a importância de valorizar e conhecer os povos indígenas no Brasil, pois são trabalhos que retratam a riqueza de culturas e histórias que não são contadas nos livros e materiais didáticos oferecidos pelo MEC e Secretarias Estaduais de Educação nas escolas de Ensino Médio. (LEAL, 2018, p. 110).

Pode ser observada a prevalência de uma concepção técnica tanto da aprendizagem como do trabaIho docente, a partir do modelo da racionalidade técnica, em que se acredita, conforme Diniz-Pereira (2014, p. 36) que "[...] para se preparar o profissional da educação, conteúdo científico e/ou pedagógico é necessário, o qual servirá de apoio para sua prática. Durante a prática, professores devem aplicar tais conhecimentos e habilidades científicos e/ou pedagógicos."
Questionando esse modelo, Imbernón (2002, p. 69) afirma que "[...] já não podemos entender a formação permanente apenas como atualização científica, pedagógica e cultural do professor, e sim, sobretudo como a descoberta da teoria para organizá-la, fundamentá-la, revisá-la e combatê-la, se preciso."

O conteúdo científico ou pedagógico fornecido pelo pesquisador foi uma espécie de manual ou coletânea, que seria disponibilizado aos professores do ensino médio, sem a previsão, inclusive, de encontros formativos, ou seja, espera-se que o professor tão-somente acate as sugestões, sem a necessidade de que seja convencido ou discuta sua importância ou relevância.

\section{CONSIDERAÇÕES FINAIS}

A análise das propostas de intervenção apresentadas nas 38 dissertações produzidas entre os anos de 2014 a 2018 na linha de pesquisa Formação de Professores e Diversidade do Profeduc/UEMS sinaliza que, embora um número expressivo de trabalhos (11 propostas, o que corresponde a $30 \%$ do total), tenha apontado para uma concepção de aprendizagem docente em uma perspectiva não transmissiva e verticalizada, persiste a predominância de uma concepção conservadora de formação, nomeada por Cochran-Smith e Lytle (1999) de conhecimento-para-a-prática.

Um total de 27 propostas (70\%) foi construído em torno da ideia de cursos, palestras, oficinas ou disponibilização de manuais, ainda que em uma ou outra apareça, entre os objetivos específicos, a indicação de momentos de "troca de experiências", "diálogo" ou "debate" entre os professores e formadores. A centralidade das propostas, no entanto, está na seleção prévia, pelo formador, de conteúdos que os professores devem acessar, por meio de leitura ou estudo ou simplesmente da exposição pelo formador, para que tenham condições de modificar suas práticas, consideradas, de alguma forma, incorretas ou insuficientes para promover a aprendizagem ou a abordagem adequada das diferentes temáticas investigadas pelos mestrandos.

O sentido das formações propostas, portanto, vai 
ao encontro da ideia de complementação da formação inicial e não da perspectiva do desenvolvimento profissional docente, em que se entende que a aprendizagem dos docentes é um processo contínuo, que se realiza ao longo da vida profissional e é impulsionado pelas necessidades formativas.

A identificação dessas necessidades formativas, conforme Correia, Lopes e Felgueiras (1994, p. 5-7), não é neutra. Antes, a escolha prévia pelos formadores daquilo que consideram serem necessidades de formação profissional dos professores reflete as "[...] relações de poder que são facilitadoras da expressão de determinados interesses em detrimento de outros" e pode "privilegiar um modelo de profissionalidade estruturado em torno da expertise didática." $\mathrm{Ou}$ seja, quando não há a participação dos professores na decisão sobre aquilo que, para eles, consiste em uma necessidade formativa, são os formadores - no caso aqui analisado os mestrandos ou aqueles que eles elegem para cumprir o papel de formador, que podem ser os coordenadores pedagógicos, diretores ou técnicos das secretarias de educação - que decidem verticalmente os conhecimentos que o professor precisa ter acesso para desempenhar de forma eficaz a sua prática.

Nesse sentido, Marcelo Garcia (2010, p. 25) aponta:

Alguns autores estão chamando a atenção sobre a ironia implícita no fato de que ao mesmo tempo que se tenta convencer os professores e as escolas de que deveriam ser mais autônomos e responsáveis pelas próprias necessidades, também se está instruindo como devem ser seus resultados e como devem abordar as prioridades nacionais para melhorar as posições que se obtêm nos estudos internacionais. Supõe-se que os professores estão tendo mais autonomia escolar precisamente no mesmo momento em que os parâmetros com os quais se espera que trabalhem e mediante os quais serão avaliados estão sendo cada vez mais demarcados e limitados. (GARCIA, 2010, p.25).

Defender que os professores necessitam ser considerados capazes de explicitar suas necessidades formativas e que podem participar ativamente da construção colaborativa dos conhecimentos que os auxiliariam a resolver os problemas que encontram em sua prática cotidiana não significa afirmar que essas necessidades não possam ser provocadas. De fato, pensar na formação de comunidades colaborativas de aprendizagem ou na "desprivatização das práticas" (COCHRAN-SMITH E LYTLE, 1999) implica considerar a dimensão coletiva de identificação dos problemas e busca de soluções, o que, de certa forma, ocorre no espaço formativo que constitui o mestrado profissional.

Sob essa ótica, compreendemos que as propostas de intervenção foram produzidas a partir de problemas de pesquisa investigados pelos mestrandos, os quais estavam, por sua vez, inseridos nos contextos que pesquisavam e podiam observar as situações de um ponto de vista privilegiado: de quem conhecia a realidade concreta pesquisada e a analisava de uma forma mais ampla, discutindo-a com os professores orientadores e com os membros das bancas de qualificação e defesa. No entanto, não se pode esperar que as experiências formativas dos mestrandos, que passaram por um processo de estudo, discussão, produção e análise de dados durante o período do mestrado, possam ser "transmitidas" aos professores da educação básica destinatários das propostas de intervenção em alguns encontros formativos, como se fosse suficiente fornece-lhes alguns dos materiais estudados pelos mestrandos para provocar-Ihes uma experiência idêntica.

É essa visão transmissiva e reprodutora da formação que percebemos estar presente na maioria das 38 propostas de intervenção analisadas. Isso nos faz questionar: essa concepção estaria de alguma forma também implícita na prática dos professores da pós-graduação? Ou o processo formativo do mestrado não teria sido suficiente para abalar as concepções que os mestrandos traziam consigo anteriormente?

Ao apresentarem propostas de intervenção que partem do princípio que é suficiente para a formação dos professores o acesso às teorias pensadas de forma exógena à escola, os mestrandos deixam transparecer a concepção de que "[...] saber mais conteúdo, mais teorias de educação, mais pedagogia, mais estratégias de ensino garante uma prática bem-sucedida" (CRUZ; ANDRÉ, 2014, p. 188), exatamente o conhecimento-para-a-prática, em que, segundo Cochran-Smith e Lytle (1999, p. 263), presume-se "[...] 
que os profissionais são solucionadores de problemas e que os problemas da prática profissional [...] podem ser resolvidos instrumentalmente através da aplicação de teorias e técnicas embasadas na pesquisa acadêmica."

Uma particularidade do mestrado profissional é exatamente a possibilidade de que os professores e demais profissionais da educação básica possam produzir conhecimento a partir da investigação de problemas encontrados em sua prática profissional, ou seja, permite a instituição de um processo formativo em que, conforme Autor 1, Autor 2 e Ribeiro (2015, p. 66), "[...] a articulação entre teoria e prática não é apenas possível, mas necessária". As referidas autoras consideram que o mestrado profissional posse se configurar no que Zeichner (2010, p. 487) denomina de "espaço híbrido" ou "terceiro espaço formativo", no qual se propicia o estabelecimento de "[...] uma relação mais equilibrada e dialética entre o conhecimento acadêmico e o da prática profissional".

Sob essa ótica, reconhecemos a relevância do Programa de Mestrado Profissional em Educação da UEMS para a formação dos profissionais da educação básica no contexto sul-mato-grossense. Ressaltamos, no entanto, que denominar os trabalhos finais de propostas de intervenção e não de produtos não é o suficiente para se demarcar um posicionamento a favor de uma concepção de formação que supere a perspectiva da racionalidade técnica ou de aprendizagem docente de um conhecimento-para-a-prática. As propostas de intervenção, como ponto de partida de uma produção acadêmica que têm alcançado uma importante visibilidade nas secretarias estadual e municipal de educação de Campo Grande/MS, precisam contribuir para uma mudança de compreensão dos processos formativos, visando a construção de redes colaborativas de aprendizagem e socialização dos conhecimentos produzidos por docentes sobre sua prática profissional, para que não sejam tão-somente pontos de chegada, ou seja, que não permitam a partir delas avanços nas concepções de formação dos mestrandos e dos responsáveis pela formação continuada no estado.

\section{REFERÊNCIAS}

AGUENA, Patrícia Nogueira. 0 ensino de artes visuais para alunos cegos na escola comum: retratando trajetórias e experiências. 2015. 123 f. Dissertação (Mestrado Profissional em Educação) - Universidade Estadual de Mato Grosso do Sul, Campo Grande, 2015.

ARRUDA, Mareide Lopes. 0 ritmo e o tom da atuação do coordenador pedagógico no contexto do programa Pacto Nacional pela Alfabetização na Idade Certa (Pnaic) e o desenvolvimento profissional docente em Aquidauana/ MS. 2016. 148f. Dissertação (Mestrado Profissional em Educação) - Universidade Estadual de Mato Grosso do Sul, Campo Grande, 2016.

BANZATTO, Mireli Figueiredo Chaves. A arte de semear saberes: contribuições para a formação sensível do artista docente. 2016. 107 f. Dissertação (Mestrado Profissional em Educação) - Universidade Estadual de Mato Grosso do Sul, Campo Grande, 2016.

BEZERRA, Kleiton Ramires Pires. Alfabetização cartográfica a partir do esporte de orientação. 2018. 152 f. Dissertação (Mestrado Profissional em Educação) - Universidade Estadual de Mato Grosso do Sul, Campo Grande, 2018.

BORGES, Fabiana Aparecida Cáceres. Práticas pedagógicas e formação de professores de jovens de 15 a 17 anos em distorção idade/ano: diálogos com docentes no cotidiano escolar. 2018. 150 f. Dissertação (Mestrado Profissional em Educação) - Universidade Estadual de Mato Grosso do Sul, Campo Grande, 2018.

CABRAL, Maria Arlete Leite Ribeiro. Os dilemas de uma coordenadora pedagógica frente aos desafios e possibilidades no/do/com o cotidiano escolar narrados em um diário. 2017. 153 f. Dissertação (Mestrado Profissional em Educação) - Universidade Estadual de Mato Grosso do Sul, Campo Grande, 2017.

CARR, Wilfred; KEMMIS, Stephen. Becoming critical: education, knowledge and action research. London: The Falmer Press, 1986.

CORREIA, José Alberto; LOPES, Amélia; FELGUEIRAS, Margarida Louro. Análise de necessidades na formação profissional de professores. Porto: ME / DEB, 1994.

COSTA, José Aparecido. O Atendimento Educacional Especializado do estudante com deficiência visual: entre o braile e as tecnologias computacionais. 2016. $117 \mathrm{f}$. Dissertação (Mestrado Profissional em Educação) - Universidade Estadual de Mato Grosso do Sul, Campo Grande, 2016. 
CRISTALDO, Andréia Laura. A implementação do Plano Nacional de Educação em Direitos Humanos-PNEDH no estado de Mato Grosso do Sul. 2015. 148 f. Dissertação (Mestrado Profissional em Educação) - Universidade Estadual de Mato Grosso do Sul, Campo Grande, 2015.

CUORE, Raul Enrique Cuore. Professores de matemática de escolas públicas estaduais de Campo Grande/MS, a lei federal no 10.639/2003 e a etnomatemática: uma articulação possível? 2016. 194 f. Dissertação (Mestrado Profissional em Educação) - Universidade Estadual de Mato Grosso do Sul, Campo Grande, 2016.

FERREIRA, Maria Cícera. Plano Estadual de Educação de Mato Grosso do Sul (2014-2024): atendimento educacional especializado na educação infantil. 2018. 147 f. Dissertação (Mestrado Profissional em Educação) - Universidade Estadual de Mato Grosso do Sul, Campo Grande, 2018.

HENKIN, Rosana Monti. Formação de professores(as) em gênero, raça e etnia: contribuições do projeto gênero e diversidade na escola. 2015. 112 f. Dissertação (Mestrado Profissional em Educação) - Universidade Estadual de Mato Grosso do Sul, Campo Grande, 2015.

GALVÃO, Paulo Eduardo Silva. A escolarização do estudante com deficiência intelectual: os cadernos escolares como recursos didáticos em análise. 2016. 96 f. Dissertação (Mestrado Profissional em Educação) - Universidade Estadual de Mato Grosso do Sul, Campo Grande, 2016.

GONÇALVES, Yong Shim. Cadernos de alunos (des)velam: o que há de pantaneiro na escola pantaneira? 2018. 178 f. Dissertação (Mestrado Profissional em Educação) - Universidade Estadual de Mato Grosso do Sul, Campo Grande, 2018.

IMBERNÓN, Francisco. Formação docente e profissional: formar-se para a mudança e a incerteza. São Paulo: Cortez, 2002

KELLERMANN, Celi Traude. As narrativas de professoras alfabetizadoras desvelando as implicações da Provinha Brasil. 2016. 157 f. Dissertação (Mestrado Profissional em Educação) - Universidade Estadual de Mato Grosso do Sul, Campo Grande, 2016.

LEAL, Sanderson Pereira. Educação, currículo e diferenças: uma análise da temática indígena no referencial curricular e nos livros didáticos do ensino médio de Mato Grosso do Sul. 2018. 111 f. Dissertação (Mestrado Profissional em Educação) - Universidade Estadual de Mato Grosso do Sul, Campo Grande, 2018.

LIMA, Edinalvo Raimundo de. A formação de professores no Plano de Ações Articuladas (PAR): a materialização das ações na rede municipal de ensino de Bataguassu-MS. 2015. 170 f. Dissertação (Mestrado Profissional em Educação) - Universidade Estadual de Mato Grosso do Sul, Campo Grande, 2015.

LOUREIRO, Maristela Sanchez. A dança no currículo de Educação Física: pressupostos e análise do projeto político pedagógico de cinco escolas de Campo Grande-MS. 2018. 118 f. Dissertação (Mestrado Profissional em Educação) - Universidade Estadual de Mato Grosso do Sul, Campo Grande, 2018.

LUIZ, Dalila. A prática pedagógica de professores Terena: o uso de "temas geradores" no processo de alfabetização. 2016. 111 f. Dissertação (Mestrado Profissional em Educação) - Universidade Estadual de Mato Grosso do Sul, Campo Grande, 2016.

MACIEL, Aline Mara Alves. O trabalho didático da escola de tempo integral na escolarização do aluno com deficiência intelectual. 2015. 118 f. Dissertação (Mestrado Profissional em Educação) - Universidade Estadual de Mato Grosso do Sul, Campo Grande, 2015.

MARECO, Maria Joana Durbem. Avaliação Nacional da Alfabetização sob a ótica das formações do Pacto Nacional pela Alfabetização na Idade Certa no estado de Mato Grosso do Sul entre os anos de 2013 a 2016. 2018. 156 f. Dissertação (Mestrado Profissional em Educação) - Universidade Estadual de Mato Grosso do Sul, Campo Grande, 2018.

MARQUES, Edilmar Galeano. O Serviço de Informação Profissional na Escola Estadual Hércules Maymone, Campo Grande/MS. 2015. 137 f. Dissertação (Mestrado Profissional em Educação) - Universidade Estadual de Mato Grosso do Sul, Campo Grande, 2015.

MONTEIRO, José Carlos. O processo de inclusão de crianças com deficiência na educação infantil: desafios da prática pedagógica. 2015. 130 f. Dissertação (Mestrado Profissional em Educação) - Universidade Estadual de Mato Grosso do Sul, Campo Grande, 2015.

NOGUEIRA, Melissa Azevedo A formação de professores de música no Estado de Mato Grosso do Sul e o diálogo com a educação básica. 2017. 203 f. Dissertação (Mestrado Profissional em Educação) - Universidade Estadual de Mato Grosso do Sul, Campo Grande, 2017.

RIBEIRO, Fernando Fidelis. Uma escalada sinuosa pelo terreno das narrativas (auto)biográficas em busca da (re)constituição docente frente a alunos com altas habilidades/superdotação. 2017. 177 f. Dissertação (Mestrado Profissional em Educação) - Universidade Estadual de Mato Grosso do Sul, Campo Grande, 2017. 
RIBEIRO, Lindalva Souza. A prática docente sob o olhar das crianças: o que vivem e o que expressam. 2014. 142 f. Dissertação (Mestrado Profissional em Educação) - Universidade Estadual de Mato Grosso do Sul, Campo Grande, 2014.

SALGADO, Roberta de Souza. Relações de gênero e sexualidade: vozes de professores/as do 9o ano do Ensino Fundamental, Campo Grande, MS. 2018. 105 f. Dissertação (Mestrado Profissional em Educação) - Universidade Estadual de Mato Grosso do Sul, Campo Grande, 2018..

SILVA, Dayse Centurion da. O Plano de Desenvolvimento da Escola como estratégia de democratização da gestão escolar: limites e possibilidades. 2016. 120f. Dissertação (Mestrado Profissional em Educação) - Universidade Estadual de Mato Grosso do Sul, Campo Grande, 2016.

SILVA, Franciele Cristina da. $\mathbf{O}$ atendimento educacional especializado para estudantes com deficiência auditiva/ surdez: o uso das tecnologias assistivas. 2018. 124 f. Dissertação (Mestrado Profissional em Educação) - Universidade Estadual de Mato Grosso do Sul, Campo Grande, 2018.

SILVA, Lenine Ferreira da. Coordenador pedagógico: a formação continuada na Rede Municipal de Ensino de Campo Grande-MS. 2016. 135 f. Dissertação (Mestrado Profissional em Educação) - Universidade Estadual de Mato Grosso do Sul, Campo Grande, 2016.

SILVA, Rosa Maria. Educação do campo \& educação em tempo integral nas escolas municipais rurais de educação integral Monte Azul e Eutrópia Gomes Pedroso, Corumbá/MS. 2017. 140 f. Dissertação (Mestrado Profissional em Educação) - Universidade Estadual de Mato Grosso do Sul, Campo Grande, 2017.

SILVA SOBRINHO, Karine. Jovem indígena Terena de Mato Grosso do Sul: identidade, formação e trajetória. 2016. 94f. Dissertação (Mestrado Profissional em Educação) - Universidade Estadual de Mato Grosso do Sul, Campo Grande, 2016.

STREIT, Rosa Neiva. Provinha Brasil: um estudo sobre a sua aplicação em escolas da Rede Municipal de Ensino de Campo Grande /MS. 2018. 137 f. Dissertação (Mestrado Profissional em Educação) - Universidade Estadual de Mato Grosso do Sul, Campo Grande, 2018.
UNIVERSIDADE ESTADUAL DE MATO GROSSO DO SUL. Cursos de Pós-Graduação: Interações com a Sociedade. 2019a. Disponível em: http://www.uems.br/pos_graduacao/detalhes/educacao-campo-grande-mestrado-profissional/interacoes_sociedade Acesso em: 27 mar. 2019.

UNIVERSIDADE ESTADUAL DE MATO GROSSO DO SUL. Cursos de Pós-Graduação: Banco de Teses e Dissertações. 2019b. Disponível em: http://www.uems.br/pos_graduacao/detalhes/educacao-campo-grande-mestrado-profissional/teses_dissertacoesAcesso em: 27 mar. 2019.

VENTURA, Micilene Teodoro. O processo de alfabetização na concepção dos professores Terena da Aldeia Bananal. 2015. $146 \mathrm{f}$.

VIEIRA, Mauricio Macedo. Percursos da implantação do projeto Traje: Travessia Educacional do Jovem Estudante Campo-grandense na escola Municipal Osvaldo Cruz em Campo Grande/MS. 2015. 129 f. Dissertação (Mestrado Profissional em Educação) - Universidade Estadual de Mato Grosso do Sul, Campo Grande, 2015.

VILAMAIOR, Maria Elisa. Rodas de leitura na primeira infância: formação de leitores e valores humanos em uma escola municipal de Campo Grande, MS. 2018. 245 f. Dissertação (Mestrado Profissional em Educação) - Universidade Estadual de Mato Grosso do Sul, Campo Grande, 2018.

VILELA, André Afonso. Diálogos hermenêuticos e narrativas autopoiéticas sobre o desenvolvimento profissional docente no/do início da docência. 2015. 141 f. Dissertação (Mestrado Profissional em Educação) - Universidade Estadual de Mato Grosso do Sul, Campo Grande, 2015.

ZEICHNER, Ken. Repensando as conexões entre a formação na universidade e as experiências de campo na formação de professores em faculdades e universidades. Educação, Santa Maria, v. 35, n. 3, p. 479-504, set./dez. 2010. 